\title{
Oxovanadium Complexes in Bio Medical Applications
}

\author{
Jyothy Gopurathinkal Vijayan* \\ Department of Chemistry, Christ University, India
}

Received:March 16, 2018; Published: March 29, 2018

*Corresponding author: Jyothy Gopurathinkal Vijayan, Department of Chemistry, Christ University, Bengaluru-29, India,

Email: jyothy.vijayan@res.christuniversity.in

Abstract

Coordination chemistry of Vanadium is largely dependent on the oxidation reduction characteristics of metal center. Vanadium and its oxoions ie, vanadium (IV) and (V) are used as efficient inhibitors of phosphate metabolizing enzymes and also perform as activators. Vanadium oxo-ions are very crucial agents as insulin enhancing agents and anti-tumor agents. These oxo-ions exhibit redox properties under physiological conditions. They are very efficient and act as a cofactor for enzymes in blood sugar metabolism, lipid and cholesterol metabolism and hormone production. Advancements in the medicinal applications of oxovanadium complexes have stimulated their design and synthesis.

Keyword: Insulin Enhancing Agents; Anti-Tumor Agents; Blood sugar metabolism

\section{Introduction}

Oxovanadium complexes are known as potential inhibitors of different enzymes. Oxovanadium complexes have a variety of application in biological, clinical and analytical fields. Oxovanadium complexes with Schiff based ligands have wild application in catalysis, antibacterial properties, medicine and anti-oxidative properties [1,2]. Complexes with Schiff based ligands attracted many researchers due to its chelating properties and change in biological characteristics [3]. Different types of oxovnadium complexes were synthesized, characterized and analyzed recently. Increased importance of oxovanadium complexes are due to its significance in biological systems and affinity towards the donor ligands. Vanadyl ion is less harmful to the environment than vanadate ion [4]. Oxovanadium complexes can activate many signaling pathways and transcription factors which help in therapeutic applications. Oxovanadium complexes with strong chelating ligands are very efficient in living system because of its ability to uptake and transport of metals inside the cells [5].

\section{Anti-Microbial Agents}

Oxovanadium complexes are found to be highly active against microbes. Chohan et al. [6] had synthesized oxovanadium complex of triazole derived Schiff bases and studied the antimicrobial properties of the compounds. They found out the complexes in vitro activity against four gram negative and two gram positive bacteria [6]. Schiff based ligands have the capacity to coordinate varying elements and to stabilize them in different oxidation states. Sahani et al had synthesized nano sized oxovanadium complexes where indoline -2,3-dione was the prepared ligand. They studied the anti-fungal activity and result showed higher activity against Aspergillusniger [7]. The existence some bacteria against antibiotics caused. The emergence of new antibacterial agents which provides satisfactory results microbes.

Heidari et al. [8] had prepared oxovanadium (IV) dimer complexes with methoxy bridging and applied it against E-Coli [8]. Bishayee et al have synthesized Schifff based oxovanadium complexes and studied antifungal activity against A. niger and A. Flavus [9]. Amoebiasis is a disease caused by protozoan parasite Entamoebahistolica. Many studies were done to prevent the growth and spread of the parasite. Maurya et al had synthesized thihydrazone based oxovanadium complexes and analyzed its result. The result showed the effectiveness of complexes against the microbes [10]. Panchal have prepared oxovanadium complexes containing thiophene-o-carboxaldene aniline and thiopheneo-carboxaldene-p-anisidene shows octahedral geometry .The compound are good bactericidal under experimental conditions. Disc diffusion method was used to test the complexes for their antimicrobial activities against salmonella typhi and e-coli [11].

\section{Anti-Diabetic Agents}

Vanadium complexes were used as therapeutic agents to cure diabetes mellitus for the last few years. Takino et al had synthesized bis (5-iodopicolinato) oxovnadium complexes and used for the treatment of in-vitro and in-vivo insulinometric analysis, they discovered the ability of the complex as an anti-microbial drug [12]. It is very essential to prepare orally effective drugs to substitute insulin injection for diabetic treatment. Oxovanadium complexes 
with insulin mimetic properties have been recently suggested as a candidate for antidiabetic drug preparation. Adachi et al prepared bis (allixinato) oxovanadium (IV) complex and used against DM. Result showed the effectiveness of the complexes towards antidiabetic therapy [13]. Glucose lowering potential of oxovandium complexes is very unique as compared with the therapeutics of other drugs for diabetics. Xie et al. had synthesized bis ( $\bigotimes$-furan carboxylato) oxovanadium (IV) a tested its activity as insulin enhancing agents. The result showed that the complex exerted antidiabetic effect in STZ-diabetic rats which boost up the sensitivity to insulin [14]. Vanadyl complexes showed antidiabetic effects in experimental animals. Many complexes proved efficient candidates for Type I and II DM. Recent studies showed that oxovanadium complexes mimic most of the physiological actions of insulin.

\section{Anti-Tumor Agents}

Vanadium complexes possess antitumor characteristics when administered at right concentrations in experimentally induced tumors. Novel therapeutic and diagonosticoxovanadium complexes are now having an impact on medical practices. Hazari et al synthesized oxovanadium (IV) Schiff base from C-substituted diamines and pyridoxal-5-phosphate [15]. The study discovered the ability of complex as antitumor agents. Oxovanadium complexes exhibit anticancer properties both in vitro and in vivo. Oxovanadium complexes displayed inhibitory effects on cancer cells metastases and reverse antineoplastic drug resistance $[16,17]$.

\section{Conclusion}

Oxovanadium complexes have the ability as anticancer agents against human cancer cells. Development of oxovanadium complexes increased the positive effects by testing it as oral therapeutic adjunct in diabetic control. Oxovanadium complexes undergo wide variety of chemistry due to the electronic and steric nature of the ligands attached to it. The biological and medicinal properties of vanadium complexes and their effects in biological systems have provided the fuel to the studies of vanadium science.

\section{References}

1. Monica Arora, Saravanan J, Mohan Shivaji, Bhattacharjee S (2013) Synthesis, characterization and antimicrobial activity of some schiff bases of 2-amino-n-(p-acetamidophenylcarboxam. Int J Pharm PharmSci 5(1): 315-319.

2. Keerthi Kumar CT, Keshavayya J, Rajesh T, Peethambar SK (2013) Synthesis, Characterization and Biological Activity Of Heterocyclic Azo Dyes Derived From 2-Aminobenzothiozole. Int J Pharm PharmSci 5(1): 13-18.

3. Huilu Wu, Fan Kou, Fei Jia, Bin Liu, Jingkun Yuan, et al. (2011) A Vshaped ligand 1,3-bis(1 methyl benzimidazol-2-yl)-2- oxapropane and its $\mathrm{Cu}(\mathrm{II})$ complex: Synthesis, crystal structure, antioxidation and DNA-binding Properties. J Photochem Photobiol B: Biolog 105(3): 190-197.

4. Frank P, Carlson RMK, Carlson EJ, Hodgson KO (2003) Mediumdependence of vanadium K-edge X-ray absorption spectra with application to blood cells from phlebobranch tunicates. Coordination Chemistry Reviews 237(1-2): 31-39.

5. Eriksson JW, Lonnroth P, Posner BI, Shaver A, Wesslau C, et al. (1996) A stable peroxovanadium compound with insulin-like action in human fat cells. Diabetologia 39(2): 235-242.

6. Chohan, Sumrra M, Youssoufi, B Hadda (2011) Metal based biologically active compounds: Design, synthesis, and antibacterial/antifungal/ cytotoxic properties of triazole-derived Schiff bases and their oxo vanadium (IV) complexes. European journal of Medicinal Chemistry 45(7): 2739-2747.

7. Sahani MK, Yadava U, Pandey OP (2014) Synthesis, spectral characterization and antimicrobial studies of nano-sized oxovanadium(IV) complexes with Schiff bases derived from 5-(phenyl/ substituted phenyl)-2-hydrazino-1,3,4-thiadiazole and indoline2,3-dione. SpectrochimicaActa Part A: Molecular and Biomolecular Spectroscopy 125: 189-194.

8. Farideh Heidari S, Jamil A, Fatemi S, Yousef Ebrahimipour, Hadi Ebrahimnejad, et al. (2017) Six-co ordinate oxo-vanadium(V) dimer complex with methoxybridging: Synthesis, crystal structure, biological activity and molecular docking. Inorganic Chemistry Communications 76: $1-4$.

9. Anupam Bishayee, Abhijeet Waghray, Mehool A, Patel Malay Chatterjee (2010) Vanadium in the detection, prevention and treatment of cancer: The in vivo evidence. Cancer Letters 294(1): 1-12.

10. Mannar R Maurya, Amit Kumar, Abdul R Bhat, Amir Azam, Cerstin Bader, et al. (2006) Dioxo- and Oxovanadium(V) Complexes of Thiohydrazone ONS Donor Ligands: Synthesis, Characterization, Reactivity, and Antiamoebic Activity. Inorg Chem 45(3): 1260-1269.

11. Pragnesh K Panchal, Hitesh M Parekh, Pramod B Pansuriya, Mohan $\mathrm{N}$ Patel (2006) Bactericidal activity = of different oxovanadium (IV) complexes with Schiff bases and application of chelation theory. Journal of Enzyme Inhibition and Medicinal Chemistry 21(2): 203-209.

12. Toshikazu Takino, HiroyukiYasui, AkiraYoshitake (2000) A new halogenated antidiabeticvanadyl complex, bis (5- iodopicolinato) oxovanadium(IV): In vitro and in vivo insulinometric evaluation. J Biol In organic Chem 6: 133-142.

13. Adachi Y, Yoshida J, Kodera Y, Katoh A, Takada J (2006) Bis (allixinato) oxovanadium(IV) Complex Is a Potent Antidiabetic Agent: Studies on Structure-Activity Relationship for a Series of Hydroxy pyrone-Vanadium Complexes. J Med Chem 49(11): 3251-3256.

14. Xie M, Gao L, Li L, Liu W, Yan S (2004) A new orally active anti diabetic vanadyl complex-bis(a-furancarboxylato)oxovanadium(IV). Journal of Inorganic Biochemistry 99(2): 546-551.

15. Hazari PP, Pandey AK, Chaturvedi S, Tiwari AK, Chandna S, et al. (2012) Synthesis of Oxovanadium (IV) Schiff base Complexes derived from C-substituted Diamines and Pyridoxal-5-Phosphate as Antitumor Agents. ChemBiol Drug Des 79(2): 223-234.

16. Chowdhury SA, Kishino K, Satoh R, Hashimoto K, Kikuchi H, et al. (2005) Tumor-specificity and apoptosis-inducing activity of stilbenes and flavonoids. Anticancer Res 25(3): 2055-2064.

17. D’Cruz OJ, Dong Y, Uckun FM (1999) Spermicidal activity of oxovanadium (IV) complexes of 1,10-phenanthroline, 2,29- bipyridal, 59-bromo-29hydroxyacetophenone and derivatives in humans. Biol Reprod 60(2): 435-444. 


\section{(c) (i) This work is licensed under Creative}

Submission Link: https://biomedres.us/submit-manuscript.php

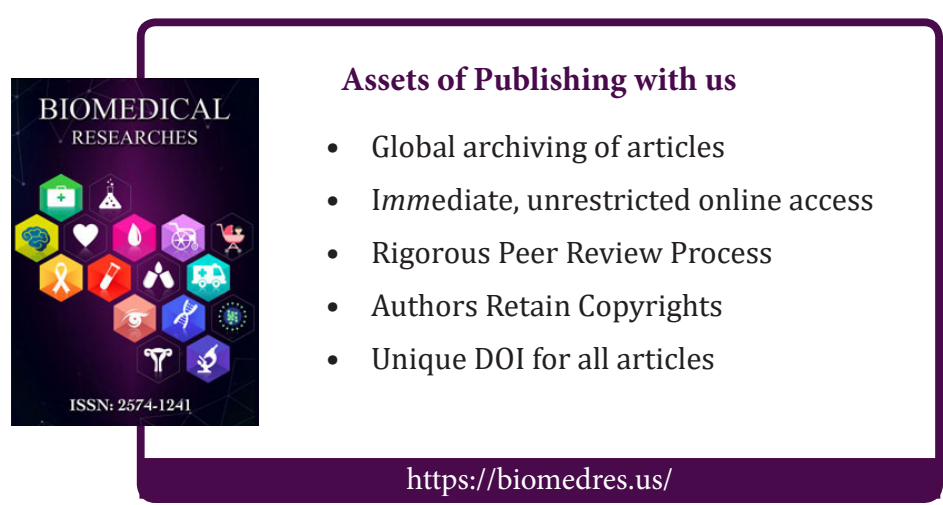

